\title{
Receptor-Type Tyrosine-Protein Phosphatase Beta
}

National Cancer Institute

\section{Source}

National Cancer Institute. Receptor-Type Tyrosine-Protein Phosphatase Beta. NCI

Thesaurus. Code C122911.

Receptor-type tyrosine-protein phosphatase beta (1997 aa, 224 kDa) is encoded by the human PTPRB gene. This protein is involved in both blood vessel maintenance and protein dephosphorylation. 